\title{
Statistical Analysis of Some Mechanical Characteristics of Glass Fiber Reinforced Composites
}

\author{
PAULINA SPANU1*, CATALIN GHEORGHE AMZA', GABRIELA DINU ${ }^{1}$ \\ UUniversity Politehnica of Bucharest, 313 Spl. Independentei, 060042, Bucharest, Romania
}

\begin{abstract}
This paper presents the results of the experimental researches obtained in the three-point test of the glassfiber-reinforced polymeric composites. Mathematical modeling of experimental results was performed using a virtual instrument (VI) developed in the graphical programming language called LabVIEW. In order to process the experimental data and display the results, the virtual instrument (VI) allows both the reading of experimental data from a saved text file from the same folder as the current VI file and the direct entry of experimental values into a control element disposed on its front panel. The virtual instrument described in this article is part of a more complex project used for the mathematical modeling of the experimental data obtained in determining the physic-mechanical characteristics of glass fiber randomly reinforced polymeric composites.
\end{abstract}

Keywords: three point bending, composites, uncertainty of measurement, LabVIEW

Glass fiber randomly reinforced polymeric composites have different physico-mechanical characteristics from those of their constituent materials. The properties of the polymeric composites vary in the very large limits, depending on numerous factors. The main factors that influence the mechanical characteristics of polymeric composites are the following [1]: the type of constituent materials, the percent fiber content, the shape and dimensions of the reinforcing elements, the way they are arranged into the matrix, the technological conditions for obtaining the constituent materials, the interface between the fibers and the matrix, manufacturing technology of composites, etc.

Flexural strength is one of the mechanical characteristics of glass - fiber reinforced randomly polymer composites that have a significant influence on the working behavior of products made from these materials. The studied materials are characterized by a high degree of inhomogeneity and therefore, the experimental values obtained for the bending strength, after testing of some specimens taken from the same blank, belong to a wide range. Considering the wide field of dispersion of the values obtained in the three point bending test of the studied polymeric composites, it is necessary to report the results of the measured values accompanied by the uncertainty of measurement associated with these results.

According to SR 13005: 2003, measurement uncertainty is a parameter associated with the result of a measurement, which characterizes the dispersion of values that are attributed to the measurement [2].

The mathematical modeling of the experimental values described in this paper was performed using a virtual instrument (VI) developed in LabVIEW graphical programming language. The virtual instrument can be used by engineers or specialists in the field of composite materials to design and optimize the physical-mechanical properties of polymeric composites with a high accuracy and in a very short period of time.

\section{Experimental part}

The experimental results described in this work were obtained using the three point bending test method regulated by the SR EN ISO 14125: 2000 / AC: 2003. According to this standard, the specimens were sampled from a composite made from AROPOL S 599 polyester resin matrix, reinforced randomly with $40 \%$ glass fiber EC 12-2400 type. The half-finished material was obtained by the spray-forming process.

For composite materials obtained by the spray-forming process, it is recommended a maximum of $40 \%$ reinforcement when material of staple fibers is used and up to $60 \%$ if long fibers are used [3-5]. The flexural strength and modulus of elasticity of a glass fiber reinforced polymeric composite increase proportionally with the percentage of the reinforcement elements, but at a content greater than $60 \%$ the flexural strength decreases mainly due to the worsening of the interfacial bonds between the matrix and the reinforcement element $[6,7]$. Therefore, the flexural strength of the polymeric composites depends significantly on the quality of the coupling agent applied to the reinforcement material. A silane coupling agent was used to improve the interfacial bonds between the matrix and the reinforcement element of the investigated composite materials.

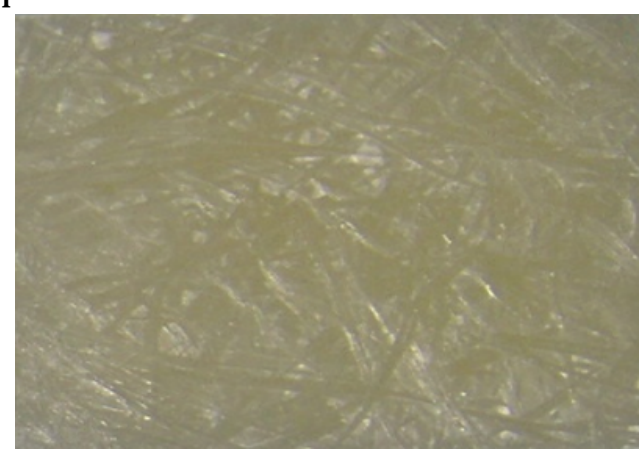

Fig 1. The half-finished product 


\begin{tabular}{|c|c|c|c|}
\hline No. sample & $\begin{array}{c}\mathbf{L} \\
{[\mathbf{m m}]}\end{array}$ & $\begin{array}{c}\mathbf{b} \\
{[\mathbf{m m}]}\end{array}$ & $\begin{array}{c}\mathbf{h} \\
{[\mathbf{m m}]}\end{array}$ \\
\hline S 1 & 80.20 & 10 & 4.10 \\
\hline S 2 & 80.10 & 10.17 & 4.16 \\
\hline S 3 & 80 & 10.40 & 4.00 \\
\hline S 4 & 80.30 & 10.23 & 4.12 \\
\hline S 5 & 80.26 & 10.25 & 4.18 \\
\hline
\end{tabular}

Table 1

DIMENSIONS OF SAMPLES

Figure 1 shows the half-finished product with the following dimensions $300 \mathrm{~mm} \times 200 \mathrm{~mm} \times 10 \mathrm{~mm}$ that was obtained by the spray-forming process and from which the specimens were taken.

Five samples were used to emphasize the repeatability of the results. In table 1 there are presented the dimensions of samples accordina to SR EN ISO 14125: 2000.

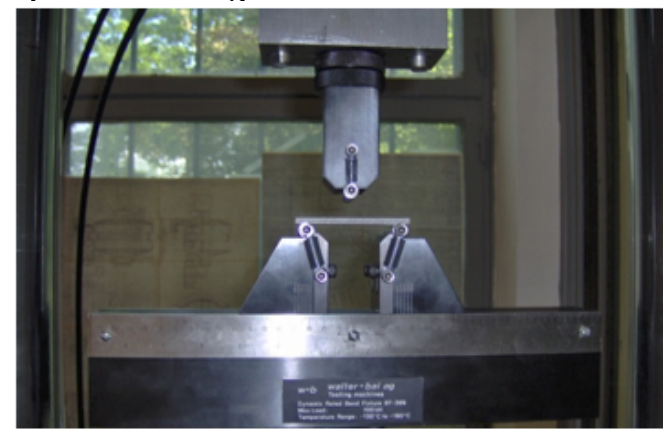

Fig 2. The universal machine LFV 25 HH WALTER-BAI
Determination of flexural strength and modulus of elasticity was performed on the universal machine LFV 25 HH WALTER-BAI (fig.2) equipped with a digital testing system of material, type EDC-580 M19.

For the determination of flexural strength, the specimens were positioned symmetrically on two supports with radius $R_{2}=5 \mathrm{~mm}$, at a distance $L=64 \mathrm{~mm}$, one against the other according to the three point bending test method as it is shown in figure 3. The load $F$ was applied with an element with radius $R_{1}=5 \mathrm{~mm}$ in the middle of the sample laid on the supports with radius $R_{2}$. Also, the figure 3 presents the length of the specimen and its thickness. The test was performed with a speed of $2 \mathrm{~mm} / \mathrm{min}$.

\section{Results and discussions}

The values of flexural strength and modulus of elasticity for the five specimens obtained using the three point bending method are shown in table 2 .

Figure 4 shows the load-displacement and stressdisplacement diagrams for the studied composites that

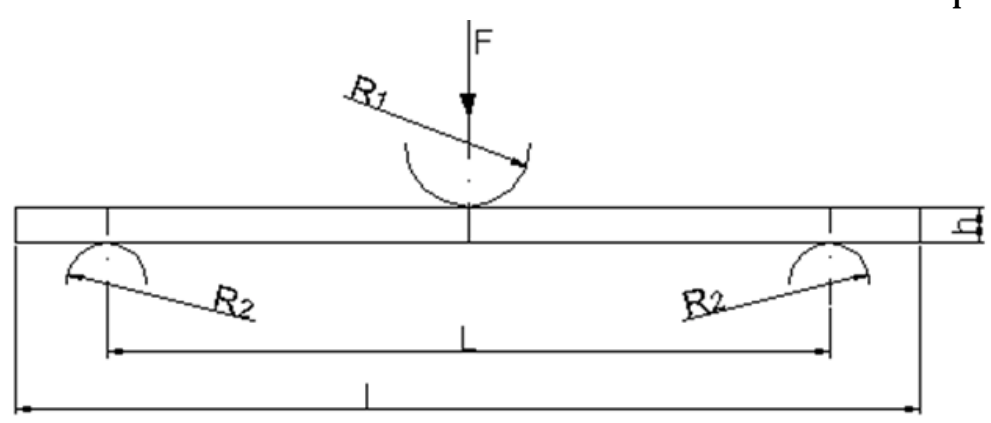

\begin{tabular}{|c|c|c|}
\hline No. sample & Flexural strength (MPa) & Flexural modulus (GPa) \\
\hline S1 & 102.23 & 3.52 \\
\hline S2 & 144.46 & 3.92 \\
\hline S3 & 99.95 & 3.46 \\
\hline S4 & 149,82 & 3.93 \\
\hline S5 & 126.78 & 3.56 \\
\hline
\end{tabular}

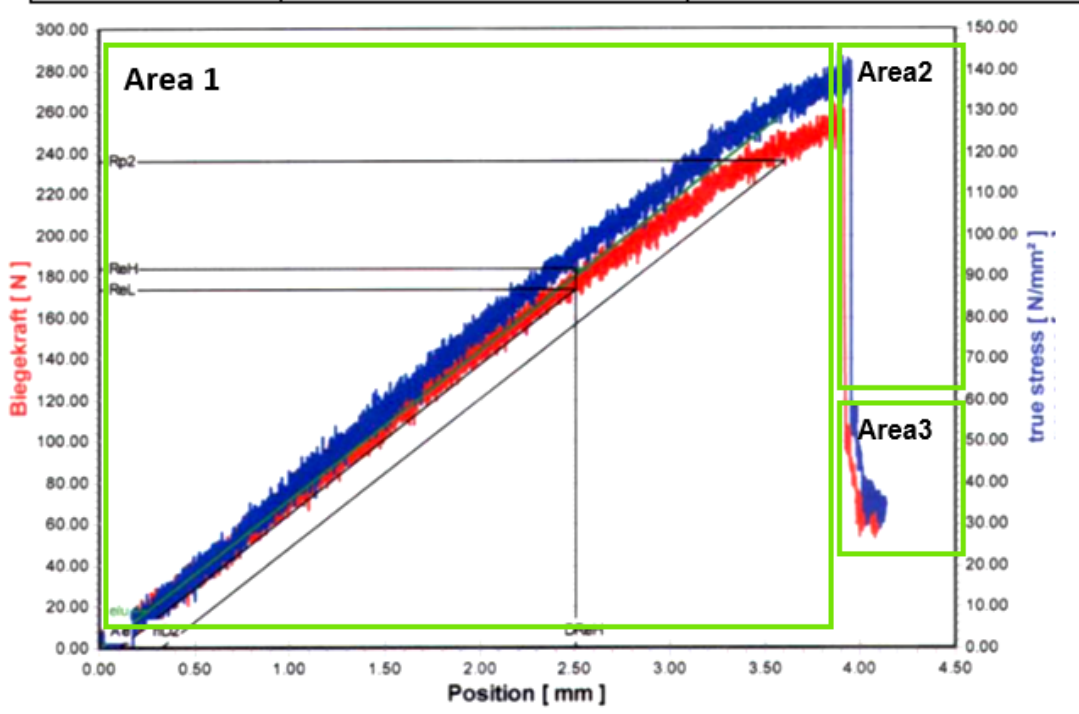

Fig. 3. Three point bending test scheme

Table 2

RESULTS OF THE EXPERIMENTAL TESTS

Fig. 4. The load-displacement and stressdisplacement diagrams 


\section{Type the values Chose a file}

\section{Type the name of the file}

test

Sample number Flexural strength (MPa) Flexural modulus (GPa) A

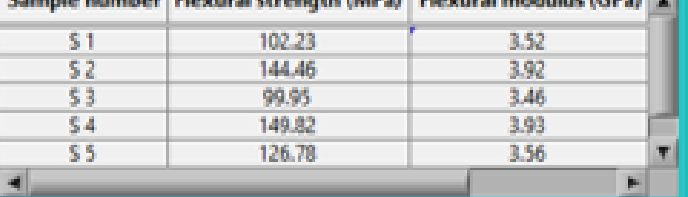

\section{Results of mathematical modeling}

\begin{tabular}{|l|c|c|}
\hline & Flexural strength (MPa) & Flexural modulus (GPa) \\
\hline Mean & 124.65 & 3.68 \\
\hline Standard deviation & 23.15 & 0.23 \\
\hline Compoused uncertainty & 10.35 & 0.10 \\
\hline Final result of the measurement & $124.65 \pm 10.35$ & $3.68+0.10$ \\
\hline & & \\
\hline 4 & & \\
\hline
\end{tabular}

Stop

Fig. 5. The front panel of the VI

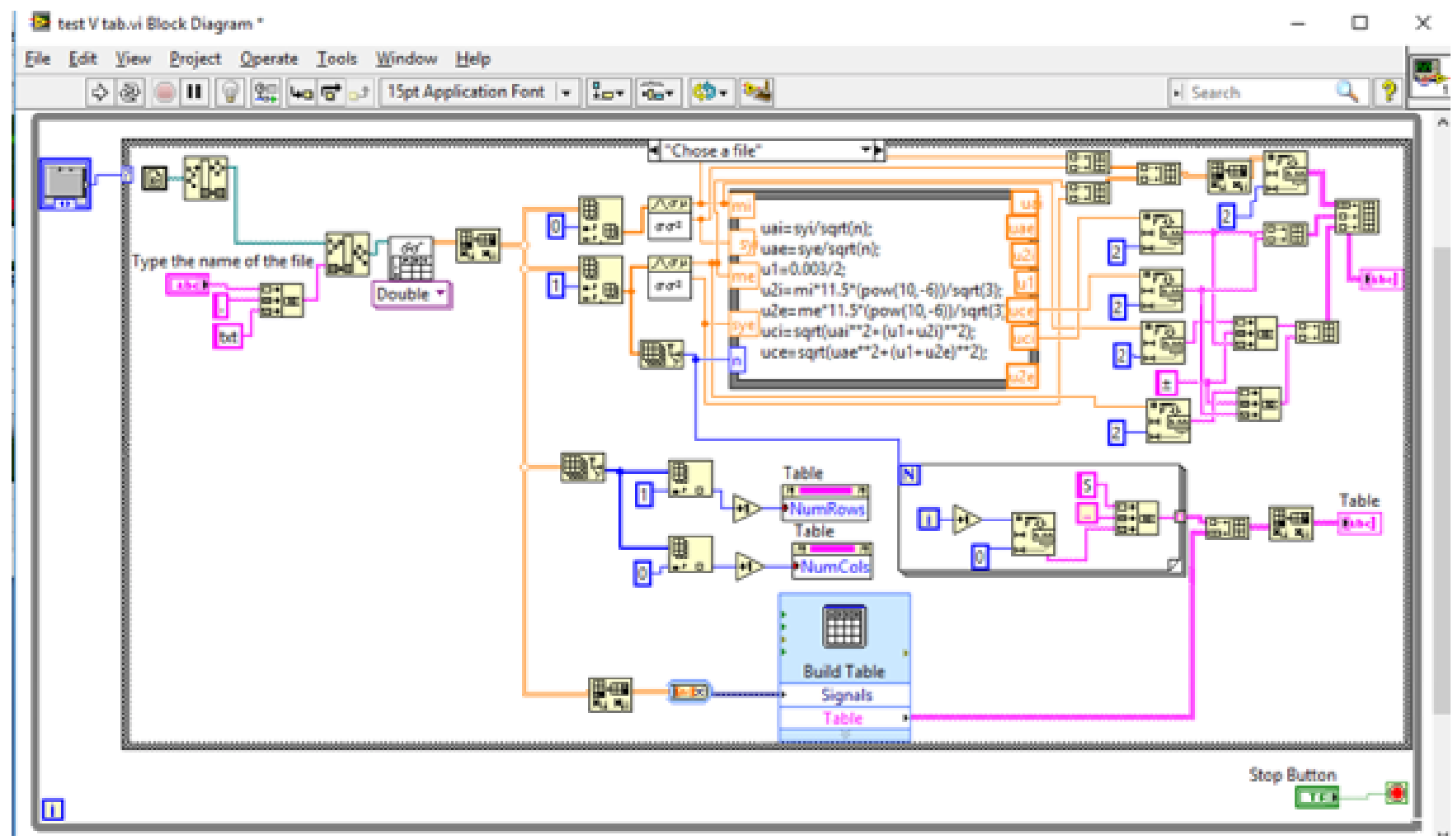

Fig. 6. The block diagram of the $\mathrm{VI}$

were obtained using digital control system type EDC-580 M19 and the DIONPRO software.

By analyzing the diagrams obtained using the three point bending test it can be revealed that they are divided in three areas:

-Area 1 - it is approximately linear, due to the elastic deformation of composite material.

- Area 2 - it is characterized by a sudden decrease of the curves that occurred after the force reached to the maximum value and it is caused by the rupture of the fiber and interlaminar bonds.

-Area 3 - it is characterized by small oscillations and appears on a relatively small portion of the diagrams in which the material continued to support the load until the final rupture of the composite.
By analyzing the specimens tested using the three point bending method, the following type of breaks were noted: the fiber breakage by stretching, break by interlaminar shearing and breaks by compressive including interlaminar shear. Considering the large field of dispersion of the experimental values obtained, caused mainly by the anisotropy of the studied material and also by the imperfections determined by the manufacturing technology of the composite, it is necessary to report the final result accompanied by the measurement uncertainty associated with the result. A virtual instrument (VI) developed in the LabVIEW graphical programming language was used for the mathematical modeling of the experimental results [8-10]. The virtual instrument allows both the reading of experimental data from a previously 
saved text file in the same folder as the current $\mathrm{VI}$ file and the direct entry of the experimental values into a control element placed on its front panel. Additionally, the application can be used to process data for an unlimited number of specimens because the control and indicator elements on the front panel of the VI will be automatically dimensioned according to the number of read or input values the user introduces. Also, on the front panel of the VI there is a TabControl element through which the user may choose to read experimental values from a file or to type the experimental values into the Array control element for numeric values (fig. 5).

The algorithm that runs the program was developed on the block diagram of the virtual instrument (fig. 6). The program allows performing computations according to the calculation formulas, regardless of the number of experimental values read or entered by the user.

On the block diagram, there were added structures and functions that allow reading data from a file to calculate the measurement uncertainty for flexural strength and for the modulus of elasticity and to write the results into the Table indicator element. The virtual instrument calculates the uncertainty compounded [2] using the formula (1):

$$
u_{c}=\sqrt{u_{A}^{2}+u_{B}^{2}}=\sqrt{u_{A}^{2}+\left(u_{1}+u_{2}\right)^{2}}
$$

where:

$u_{A}$ - represents type A uncertainty;

$u_{B}$ - type $B$ uncertainty, determined by taking into account the following components:

$u_{1}$ - the uncertainty of calibration of the measuring instruments specified in the calibration certificate;

$\mathrm{u}_{2}$ - the uncertainty of measurement due to the influence of temperature on the measurement results.

A Formula Node structure was defined to compute the standard uncertainty based on the formula (2):

$$
u_{A}=s(\bar{y})
$$

where:

$s(y)$ - represents the standard deviation of the mean, calculated using the formula (3);

$\mathrm{S}_{\mathrm{y}}$ - average experimental square deviation, calculated using the equation (4);

$\bar{y}$ - the arithmetic mean of valid results $y_{i}$ calculated using equation (5).

$$
\begin{aligned}
& s(\bar{y})=\frac{s(y)}{\sqrt{n}} \\
& s_{y}=\sqrt{\frac{\sum_{i=1}^{n}\left(y_{i}-\bar{y}\right)^{2}}{(n-1)}} \\
& \bar{y}=\frac{\sum_{i=1}^{n} y_{i}}{n}
\end{aligned}
$$

The virtual instrument computed the calibration uncertainty of the measuring instruments $u_{1}$ using the formula (6): where:

$$
u_{1}=\frac{U}{k}=\frac{0,003}{2}=0,00150[\mathrm{MPa}]
$$

$U$ represents the expanded uncertainty due to systematic errors (specified in the calibration certificate of the measuring equipment for a confidence level of $95 \%), U=$ 0.003 , for $\mathrm{k}=2$.

The measurement uncertainty $u_{2}$ due to the influence of the measuring temperature was calculated by (7):

$$
u_{2}=u(\delta t)=\frac{Y \times \alpha \times \delta t}{\sqrt{3}}
$$

where:

$Y$ - represents the nominal dimension of the measurement;

$\alpha$ - coefficient of thermal expansion of the measuring equipment $\left(\alpha=11.5 \times 10^{-6} \mathrm{~K}^{-1}\right)$;

$\Delta \mathrm{t}$ - estimated temperature variation during measurements.

The extensive uncertainty $U_{95 \%}$ was determined into Formula Node of the VI using the formula (8):

$$
(\mathrm{k}=2)
$$

$$
U_{95 \%}=k \times u_{c} \quad(\mathrm{k}=2)
$$

The virtual instrument allows the computation of the final result for the flexural strength and modulus of elasticity obtained in the three point bending test of the studied materials based on the relationship (9):

$$
X=\bar{y} \pm u_{c}
$$

When the virtual instrument is running, the following results are displayed on the indicator elements which are available on the front panel: arithmetic mean of experimental values, standard deviation, uncertainty composed and the final result of measured values with the measurement uncertainty associated with the result.

\section{Conclusions}

Research on the study of three point bending behavior of glass fiber reinforced polymer composite has highlighted the fact that their flexural strength depends on many factors. One of them is the technology of manufacturing of the composite material that has a significant influence on the obtained results because it contributes significantly to the increase in the degree of inhomogeneity of the material. The analysis of the structure behavior of the polymer composite materials studied under concrete test conditions revealed the following breakage modes of them: the fiber breakage by stretching, break by interlaminar shearing and breaks by compressive.

The values of the flexural strength and of the modulus of elasticity, obtained for the five specimens taken from the same blank, had a broad dispersion field and therefore, for the high precision reporting of the final result, the measurement uncertainty was calculated by acquiring data from a file from the same folder as the VI file. The virtual instrument is part of a complex project used for the mathematical modeling of the experimental data obtained in the determination of the physical-mechanical characteristics of the composite materials. The diagrams, the results displayed into indicator elements or written in 
different type of files are obtained using the applications of the project and are available to any engineer or specialist in the field of composite polymer materials.

\section{References}

1.PETRESCU, I., MOHORA C., ISPAS, C., U.P.B. Sci. Bull., Series D, Vol. 75, Iss. 1, 2013, p. 121

2.*** SR 13005:2003: Ghid pentru exprimarea incertitudinii de masurare 3.STEFANESCU, F., NEAGU, G., MIHAl, A., Materialele viitorului se fabrica azi; Materiale compozite, Editura Didactica si Pedagogica, Bucharest, 1996

4.MARES, M., Materiale compozite, Tipografia Universitatea Tehnica Gh. Asachi, lasi, 2002

5.ZGIRIAN, G., DEMETRESCU, I., GHEORGHIU, H., IOVU, H., HADAR, A., ATANASIU, C., Rev. Chim. (Bucharest), 56, no. 7, 2005, p. 803
6.DRAGHICI, S., PARAUSANU, I., BACIU, F., PETRESCU, H.-A., HADAR, A., PASTRAMA, St. D., Mat. Plast., 53, no. 4, 2016, p. 585

7.CORMOS, R., PETRESCU, H-Al., HADAR, A., ADIR, G.M., GHEORGHIU, H., Mat. Plast., 54, no. 1, 2017, p. 180

8.ABAZA, B., SAVU, T., SPANU, P., Algoritmi, Indrumar de laborator, Editura PRINTECH, 2014

9.SAVU, T., ABAZA, B., SPANU, P., Reprezentãri grafice, Indrumar de laborator, Editura PRINTECH, 2014

10.SPANU, P., JIGA, G., RADULESCU, M., LabVIEW Application for the Strength Calculus of an Unhomogeneous Beam, Proceeding of the $29^{\text {th }}$ International Business Information Management Conference, 2017, p. 4024

Manuscript received: 9.07.2017 